\title{
LA ANTIGÜEDAD CLÁSICA \\ SE RECIBE EN LAS ESCUELAS. REPÚBLICA, VALORES CÍVICOS Y NACIONALISMO EN LOS MANUALES DE ESCUELA MEDIA ARGENTINA (1920-1955)
}

\section{CLASSICAL ANTIQUITY AT SCHOOLS. REPUBLIC, CIVIC VALUES AND NATIONALISM IN ARGENTINE HIGH SCHOOL BOOKS (1920-1955)}

\author{
Eleonora Dell' Elicine* \\ Universidad de Buenos Aires / Universidad de General Sarmiento
}

\begin{abstract}
RESUMEN. En Argentina entre 1920 y 1955, el crecimiento sistemático de corrientes de derecha fuertemente vinculadas a la iglesia y al ejército se enmarcó y fue a su vez potenciado por la crisis del 29 y del modelo único agroexportador. En este contexto, los discursos nacionalistas y antiimperialistas cobraron fuerza inédita, encontrando canales de expresión fundamentalmente en la prensa y revistas de circulación periódica. Por diferentes razones que exploraremos a lo largo del artículo, las líneas de antagonismo que caracterizaban el debate político no acusaron una repercusión lineal en los discursos pedagógicos. Este registro flexible permitió que las sociedades antiguas constituyeran objeto de interés para un público amplio y no profesionalizado en los estudios históricos. En la actualidad, la concurrencia de un discurso nacionalista y de un discurso que ensalza lo inmediato pone en crisis seria la significatividad de estos estudios.
\end{abstract}

PALABRAS CLAVE: Recepción, Antigüedad clásica, Historia de la educación argentina, escuela secundaria, manuales.

ABSTRACT. For the period between 1920 and 1955, Argentine had a progressive increase of Right-wing trends strongly tied both to the Church and to the Army. A rise simultaneously framed and fostered by both the context of the Great Depression and the Argentinian agro-exporting model. In this context, nationalist and antiimperialist discourses expanded rapidly for their finding of mass communication means, primarily the journals and the magazines. However, the controversies that distinguished the political debate lacked, for reasons to be explored in this paper, a lineal impact on the pedagogical discourses. The result being that the esteem towards the Greek and Roman societies maintained a relevant place in the scholar curricula, and not showing the available projects acrimonious differences. This fexible scheme permitted the ancient societies to become a topic of much interest for a broad audience, no regarding their skills as professional historians. Nowadays, the convergence between a nationalist discourse and second one extolling the immediacy poses at serious risk the importance of these studies. books.

KEYWORDS: Reception, Classical Antiquity, History of Education in Argentine, High School, High School

\footnotetext{
* Correspondencia a / Correspondence to: Eleonora dell'Elicine. Universidad de Buenos Aires, Quinquela Martín 1748, 3ro «B», Ciudad de Buenos Aires, Argentina (CP 1296) - eleonoradellelicine@gmail.com - https://orcid.org/0000-0003-1942-7787.

Cómo citar / How to cite: Dell'Elicine, E. (2019), «La Antigüedad clásica se recibe en las escuelas. República, valores cívicos y nacionalismo en los manuales de escuela media argentina (1920-1955)", Veleia, 36, 137-146. (https://doi.org/10.1387/veleia.20706).
}

Recibido: 26 marzo 2019; aceptado: 4 junio 2019.

ISSN 0213-2095 - elSSN 2444-3565 / (C) 2019 UPV/EHU 
De acuerdo al último censo en la provincia de Buenos Aires — por lejos, el distrito más poblado de la República Argentina - hay 1.246.399 estudiantes entre 12 y 17 años inscriptos en los 4.178 establecimientos educativos de nivel medio ("Censo Provincial 2017, 12-13»). Durante su primer año de escuela secundaria, estos alumnos reciben en sus clases de Ciencias Sociales la siguiente formación:

«Unidad de contenidos 1: muchos mundos y el comienzo de la historia y la geografía humana. (Se estudian los ecosistemas y las bandas paleolíticas).

Unidad de contenidos II: pocos mundos y la apropiación del espacio según nuevas relaciones sociales (Se estudian las sociedades neolíticas y las nuevas espacialidades a raíz de la sedentarización y la agricultura).

Unidad de contenidos III: entre mundos, la experiencia de construcción del Occidente. Desarrollo de la división social del trabajo y transformaciones del espacio europeo (Aquí finalmente se estudian las sociedades del antiguo Oriente, Grecia, Roma y la Edad Media)» (Diseño curricular para la Educación Secundaria 2006, 75-77).

En términos prácticos, estos estudiantes reciben todo lo que la escuela tiene para decir acerca de las sociedades de la Antigüedad grecorromana en menos de un trimestre de labor. De acuerdo a los documentos oficiales, lo relevante es que los alumnos actuales reflexionen acerca de los modos de constituirse en el espacio e identifiquen las diversas maneras en las que se ha organizado el trabajo a través de la Historia. En este esquema, el Estado aparece como un avance de la $\mathrm{Hu}-$ manidad; y la proletarización, confrontada a las oscuras relaciones de esclavitud y servidumbres antiguas, se advierte como uno de sus logros más brillantes. Las posturas nacionalistas también saldan viejas deudas con lo que identifican con una educación europeizante, circunscribiendo a Argentina y a América los casos de estudio recomendados para trabajar. Vedada, para el último tramo curricular, toda posibilidad de encontrar algún ágora griega en suelo patrio, el documento sugiere a los docentes pasar por alto el tratamiento de las sociedades antiguas y centrarse únicamente en el análisis de las ciudades medievales. En definitiva y al día de hoy, los contenidos vinculados con la historia de las sociedades clásicas casi que no se imparten en las escuelas bonaerenses argentinas.

Esta reforma curricular impuesta a partir de 2006 denota un cambio profundo en las tradiciones bajo las cuales el Estado nacional, a través de uno de sus aparatos de intervención todavía más importantes, propone pensar el pasado de la sociedad argentina. Hasta tiempos recientes, la escuela en efecto sostenía la hipótesis de una inclusión del país en el mundo a través de una herencia cultural compartida: de allí la importancia de estudiar las sociedades grecorromanas y de referenciarse en Pericles, hermanos Graco, Cicerón o César.

En este trabajo he elegido examinar la recepción de la idea de Antigüedad clásica en los manuales de escuela media del periodo 1916-1955 (Finocchio 2009; Linares 2009; Berard 1995; Dussel 1997). A lo largo del periodo se estructuran orgánicamente varias tradiciones de derecha en el país — la derecha liberal, la derecha católica, la nacionalista, la corporativista, la peronista_, cruzándose muchas de ellas entre sí, con sus respectivas instituciones, órganos de difusión e intelectuales sobresalientes; mas como trataremos de demostrar, estas vertientes se valieron en la escuela de los contenidos que corresponden a las sociedades clásicas para generar adhesiones, resaltar algunos valores cívicos sobre otros y proponer, en suma, un proyecto de país. La enseñanza de la Antigüedad grecorromana constituyó en todo momento un laboratorio privilegiado para poner a circular diversas propuestas políticas inclusive entre las derechas nacionalistas. Para advertir mejor la riqueza de posturas, he decidido segmentar el periodo en tres etapas: una primera etapa liberal, bajo presiden- 
cias del Partido Radical (1916-1930); una etapa intermedia, bajo gobiernos conservadores (19301946); y finalmente una tercera etapa de hegemonía peronista (1946-1955).

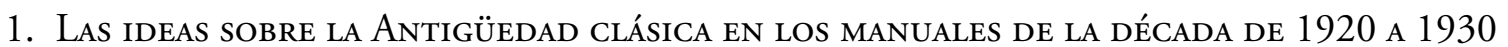

Sabido es que la Argentina, durante los años previos a la Primera Guerra, constituyó un puerto de llegada importantísimo de grandes contingentes migratorios provenientes de Europa, Rusia y el Imperio otomano. En 1914, la población inmigrante representaba el 30\% de la población total y particularmente en Buenos Aires, las estimaciones calculan entre un 60 y un $80 \%$. En ese contexto, la escuela primaria constituyó un instrumento fundamental para la elaboración de una nueva comunidad nacional; y aunque a escala menor y más restrictiva, la escuela secundaria cumplía un rol semejante.

La centralidad de la institución escolar en Argentina venía dada por la ley 1420 de Educación común, promulgada en 1884 por el entonces presidente Julio Roca. Esta norma pionera en América Latina sancionaba la educación primaria obligatoria y gratuita bajo control del Estado, con formación religiosa optativa fuera del horario escolar; siendo reforzada en todo el territorio nacional por la Ley Laínez en 1905. Siete años más tarde, en 1912, se promulgó la Ley Sáenz Peña que instituía el voto universal, secreto y obligatorio para ciudadanos argentinos varones, nativos o naturalizados. Esta norma modificó el escenario político limitando a los conservadores el control de las urnas y permitiendo el acceso al gobierno del Partido Radical junto con la participación política de las clases medias.

En este marco general y como veníamos afirmando, la enseñanza de las sociedades grecorromanas en las escuelas secundarias obedecía a la convicción de una tradición compartida, de una pertenencia a la civilización del progreso que se originaba lejanamente bajo el sol del Egeo y se expandía en el presente por todo el orbe. Un manual de 1925 explicaba a los jóvenes estudiantes la diferencia entre Esparta y Atenas en estos términos:

«[Esparta] encarnó el espíritu del orden, la virtud rígida e inflexible del militar, el coraje no como virtud sino como obligación, la intolerancia y la prepotencia como sistema; [Atenas] en cambio representó la patria de la democracia política y el centro del buen gusto y de la elegancia, (...) y donde se desarrolló una civilización tan brillante y tan profunda como nunca jamás se había verificado hasta entonces, y que sirvió y sirve de modelo en la actualidad para los pueblos amantes de la libertad, de la justicia y de la belleza armónica.» (Trevisán \& Sinland 1925, 85)

Como podemos advertir, el estudio de las sociedades antiguas en las aulas pretende dar a conocer una herencia, un patrimonio disponible para aquellas sociedades que se inclinen por la libertad y la democracia. La idea de modelo deja en claro que la relación entre la herencia y la joven nación no está completamente determinada, sino que constituye una elección, un camino esforzado que garantiza libertad, justicia, armonía social y una estética concomitante.

Esta posición de modelo a imitar que revisten las sociedades clásicas estimula a los también jóvenes lectores a identificar cuáles son las verdaderas condiciones que han asegurado el éxito de Grecia y Roma. Explicando las razones del triunfo helénico en las Guerras Médicas, así discurre otro libro publicado en 1922 :

«El pueblo de los medos carecía de homogeneidad, carecía también de espíritu nacional, y no había cohesión entre los elementos que lo componían, y es bien sabido que el sentimiento del deber y del patriotismo no prosperan jamás entre los esclavos y las turbas envilecidas, porque es pa- 
trimonio de los hombres libres. Y tampoco habían recibido la instrucción física, ni la instrucción moral, ni la instrucción cívica que es indispensable para formar ciudadanos sanos de cuerpo y de espíritu.» (Martínez 1922, 97)

Como podemos observar, las sociedades antiguas son referencias a emular porque han cumplido sus propósitos. No es cuestión de abandonar la conducción en las masas analfabetas, sino que, gobernadas con el sentido del deber, la ciencia y el patriotismo que solo se aprenden en la escuela, son capaces de alcanzar grandes objetivos. El estudio de Grecia y Roma en la escuela de los años veinte moviliza valores cívicos y se orienta claramente a formar a las nuevas generaciones de dirigentes.

Durante el periodo, el contenido de los manuales apunta a un proyecto liberal ${ }^{1}$, opuesto a los caudillismos personalistas ${ }^{2}$ y con un marcado desapego al ejército y a los valores de la guerra ${ }^{3}$. Estos libros escolares, escritos por lo general no por historiadores profesionales sino por miembros prestigiosos del cuerpo de profesores secundarios, van a tener bastante reconocimiento y éxito editorial a lo largo de generaciones, reeditándose una y otra vez — como en el caso del texto de Trevisán— hasta 1944 por lo que pude rastrear. Esto implica que las ideas liberales clásicas organizadas a través de estos contenidos historiográficos van a circular en paralelo a otras posturas que despuntan en los manuales promediando los ańos 30.

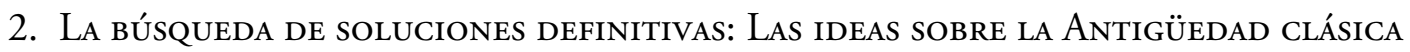 EN LOS MANUALES DE 1930 A 1946}

La crisis del 29, pero más todavía —al decir de Tulio Halperín Donghi- el desencanto respecto a las perspectivas generadas por la democracia representativa, dieron lugar a la emergencia de diferentes corrientes de pensamiento, prácticas e instituciones que ponían en cuestión las reglas de la república ${ }^{4}$.

Como venimos afirmando, las corrientes de derecha se valieron de los contenidos correspondientes a las sociedades grecorromanas para proponer nuevos valores cívicos y, con ellos, nuevos proyectos de país. Uno de los intelectuales más destacados de la derecha nacionalista, iniciador de la corriente revisionista de la historiografía liberal en Argentina y diputado peronista entre 1946 y 1952, Ernesto Palacio (1900-1979), señala a los estudiantes a Roma como la «madre de nuestra cultura actual». Dice Palacio:

«En Roma, por lo contrario, vemos el caso sorprendente de una ciudad pequeña que poco a poco, gracias a la sola energía de sus habitantes y del auxilio de la fortuna, llega a dominar a todas

\footnotetext{
1 «El patriotismo era muy profundo en el ateniense, porque lo apoyaba a la vez en la gloria de la ciudad y en el interés personal» (Trevisán \&Sinland 1925, 89).

2 «La corrupción en Roma alcanzaba niveles alarmantes (...). En tiempos de Mario, los escándalos de Roma, las luchas civiles, las guerras sociales, las rivalidades entre los demagogos habían desnaturalizado completamente el carácter republicano de la constitución. Parecía que los romanos debían siempre obedecer a un amo: Mario, Sila, Pompeyo o César. El bienestar dependía de la honradez y habilidad del demagogo, que dirigía en un momento determinado los destinos de la República» (Trevisán \& Sinland 1925, 120).
}

\footnotetext{
3 «Grecia se difunde sin violencias, guiada por el poder del genio y del arte en sus manifestaciones superiores, en tanto que Roma solo avanza por medio de las armas, de los despojos y de las conquistas». (Martínez 1922, 87).

4 "Antes incluso de la tormenta cada vez más violenta que se desencadenó sobre el mundo a partir de 1929 - pronto vista por muchos como destinada a poner fin a la etapa floreciente de la civilización liberal y capitalista-, el régimen de democracia representativa (...) estaba lejos de apoyarse en un sólido consenso de opinión» (Halperín Donghi 2003, 23).
} 
las otras ciudades circundantes y luego a todo el territorio, y luego a todo el mundo civilizado, unificándolo en una sola cultura que es la madre de la nuestra actual. Esta irradiación desde un solo punto, debida principalmente a causas morales, es lo que hace de la historia de Roma una historia ejemplar.» (Palacio 1939, 8)

Como podemos advertir, el patriotismo ya ha dejado de ser "patrimonio de hombres libres» y se ha transformado en un sentimiento general que anida en aquellos que habitan un mismo suelo. La conquista y la uniformidad cultural son valores positivos, pero todo esto se piensa desde Roma en tanto cuna de una civilización común.

Junto a los manuales que transmitían los valores liberales de la década anterior, un conjunto nuevo de libros hace centro en los mismos contenidos movilizando en la escuela la axiología nacionalista ${ }^{5}$, la idea de un estado fuerte y sobre todo resaltando las posibilidades de las soluciones personalistas (Nieburg 1988; Rock et al. 2001; Pasquale 2009). El mismo texto de Palacio propone esta noción sin ambages. En este punto escribe:

«Era necesaria una revolución contra el capitalismo financiero cuyo órgano era el Senado, y ésta no podía hacerse con el partido popular debido a sus asambleas anárquicas y sus tribunos sobornables: debía realizarla una autoridad fuerte. Para ser fuerte, la autoridad debía concentrarse en una sola persona. Fue lo que comprendió César y Octavio.» (Palacio 1939, 123) ${ }^{6}$

El caudillo incorruptible constituye la única solución que a futuro puede venir a ordenar la crisis de instituciones y las propuestas peligrosas. Para este abogado resulta probable que la sociedad del presente no esté preparada para comprender semejantes verdades, pero puede preverse que las futuras generaciones, a través del trabajo en la escuela, estuvieran en condiciones de entender la viabilidad de la salida dictatorial como en su momento lo hicieron César y Octavio.

La derecha católica, por su parte, también va a utilizar estos contenidos para transmitir valores cívicos. Para esta corriente, no es el Estado fuerte el centro de los desvelos sino la protección de la familia (Gutiérrez \& Romero 1995). La familia y la moral del Evangelio constituyen esta vez la clave de una solución política a transitar por las futuras generaciones de argentinos. Así puede leerse en el manual de Pearson:

«La educación se desenvolvió en Esparta sobre la base del absolutismo de Estado. El Estado lo fue todo. Estaba por encima de la familia, como por encima de todo principio. Como el Estado necesitaba ser fuerte y su fuerza estribaba en los soldados que podía disponer, todo ciudadano espartano debía pertenecer al ejército. Los niños fueron, pues, más del Estado que de sus padres.» (Pearson 1938, 132)

\footnotetext{
5 Una posición diferente: «Con todo lo dicho no respondía a otro pensamiento que el de una patria potente y gloriosa, y en esa aspiración que estaba como fundida el alma de Esparta, hízose esta nación una de las expresiones más interesantes del patriotismo que nos haya legado el mundo antiguo. No es el patriotismo de nuestros días, dentro del cual cabe perfectamente la estimación del extranjero. No el patriotismo que, en lo que anhela se circunscribe a lo legítimo, contemplando como valla infranqueable contra cualquier apetito el derecho a vivir con las demás naciones de la
}

tierra; sino un patriotismo extremo, en que toda ambición territorial, los odios y la crueldad hacíanse laudables si tenían como fin favorecer al propio país» (Pearson 1938,133$)$.

6 Un poco antes recalca la misma fórmula: «El ejercicio del poder personal en beneficio público, es decir, cuando un caudillo obra como mandatario de todo un pueblo, se llama desde entonces cesarismo» (Palacio 1939, 116). El personalismo y los regímenes fuertes constituyen la única salida posible a las limitaciones de la democracia representativa. 
"Más del Estado que de sus padres...», «la autoridad debía concentrarse...», «el patrimonio de los hombres libres»..., como podemos advertir, la enseñanza de las sociedades grecorromanas en las escuelas argentinas durante los treinta constituye un campo muy diverso donde se dirimen proyectos de país bastante distintos. Una novedad del periodo lo constituye la incursión de intelectuales orgánicos en la factura de los manuales: tal es el caso de Ernesto Palacio que citábamos recién, que desde 1931 enseñó Historia y Geografía en tres escuelas medias de renombre. Palacio percibió tempranamente la proyección que ofrecía la escritura de un manual para difundir sus ideas entre nuevos públicos, y también apreció las posibilidades que otorgaba una materia prestigiosa como la Historia clásica para la reflexión sobre el presente. En 1946, en efecto, este mismo autor escribió un ensayo que tituló Catilina. La revolución contra la plutocracia en Roma.

No obstante, el amplio espectro ideológico que registraba la transmisión de la Historia Antigua a un público de futuros ciudadanos, los manuales, en todas sus vertientes y a lo largo de las dos décadas, insistían en remarcar el progreso del presente aun en relación a una de las épocas más brillantes de ese pasado compartido. En la joven nación resultaba esperable superar los límites antiguos, y los jóvenes estudiantes estaban convocados —al menos desde los libros- a conducir ese proyecto.

\section{Los CONTENIDOS DE LA ESCUELA SECUNDARIA EN EL PROYeCTO NACIONAL}

Sin sombra de dudas, la década que se abre entre 1945 y 1955 va a estar dominada por la figura potente y carismática de Juan Domingo Perón. La innovación del primer peronismo es la incorporación de las «masas» — categoría de uso peronista si las hay — al escenario político, organizadas fundamentalmente a través de sindicatos que reconocían en el líder capacidad de arbitraje y mediación. El discurso nacionalista de Perón combina de un modo completamente innovador para la Argentina varias tradiciones: la derecha católica, elementos del fascismo, y el revisionismo antiimperialista desarrollado en la década anterior por intelectuales como Palacio y otros.

En la escuela tanto primaria como secundaria, los discursos nacionalistas no rivalizan con el reconocimiento de los aportes europeos. Un manual de vertiente católica y amplísima circulación interpela de la siguiente manera a estudiantes de sexto grado:

«España en primer término entre los países descubridores y colonizadores de América, y en el siglo xIx las principales naciones de la Europa occidental y central llevaron a América —al amparo de las enseñanzas del Evangelio, hecho del amor y caridad esencial del espíritu grecolatino- la claridad del raciocinio y la expresión, la investigación metódica en el estudio, el orden en la organización política, la justicia en las relaciones sociales y la disciplina familiar en la vida doméstica.» (Astolfi, Pasquet \& De Repetto 1949, 60-61)

Como podemos advertir, los discursos escolares no oponen un nacionalismo aislado a un mundo competitivo y hostil, sino que ubican los sentimientos nacionales en el progreso de la historia, en la aparición de nuevas naciones que recogen la herencia europea y le infunden el vigor de unas condiciones materiales promisorias (Somoza Rodríguez 1997; 2006; Corbiere 1990; Artieda 2009).

El régimen peronista ciertamente cuenta en la escuela primaria con manuales que ponen a circular ideas y valores del gobierno. Inclusive a partir de 1952, la ley 14126 impone como lectura 
obligatoria el libro La Razón de mi vida — legado maestro de Eva Perón-. La relación con la escuela secundaria es, sin embargo, más espinosa. Una vez más, no es en el terreno del tratamiento de la Antigüedad clásica el lugar donde aparece el problema. Incluso en los documentos curriculares de 1953, en el cual toda la currícula de Historia cae bajo el rótulo de «Formación históricosocial y de la conciencia nacional», el programa de primer año de la escuela secundaria se extiende desde la Prehistoria a la Reconquista española; y de las 16 bolillas contenidas, seis se abocan al estudio de las sociedades clásicas.

Donde se advierte rispidez entre el régimen peronista y el cuerpo de profesores que escribe manuales es en el tratamiento de algunas figuras de la Antigüedad, particularmente alrededor de tiranos y caudillos personalistas. En varios manuales de la época, en efecto, personajes como Pisístrato canalizan la reflexión acerca de las condiciones, ventajas y limitaciones de la concentración de poder, al punto que el tirano de Atenas parece recién salido de la Casa Rosada. En un manual de 1953, en efecto, se puede leer la siguiente caracterización del Pisístrato peronista:

«Entre los caudillos populares sobresalió a mitad del siglo VI a.C. un eupátrida llamado Pisístrato, que abandonó a los de su clase para convertirse en un conductor de los pobres de las afueras de Atenas. Pisístrato fue llevado por los proletarios al gobierno de Atenas. Era un ser inteligente, sagaz y ambicioso. Deseaba mejorar las condiciones de los campesinos (...).» (Pisano 1953, 85)

No se trata de una crítica abierta - Pisístrato estaría atento, como Perón, a promocionar las condiciones de vida de las masas que lo apoyan-; sino de una advertencia sutil, el señalamiento del carácter experimental y personalista del régimen. Los manuales católicos son un poco más incisivos en la reflexión:

«La prosperidad de las ciudades produjo una emigración de los campesinos hacia ellas, donde formaron una masa cada vez mayor de obreros, marineros, empleados, comisionistas, etc., que aspiraban a mejorar sus condiciones. Esta clase social apoyó a los ricos en sus pretensiones de gobernar. Surgieron entonces caudillos audaces, ambiciosos e inteligentes, los cuales, mediante la agitación pública o motines, se adueñaron del poder. Recibieron el nombre de «tiranos», palabra que no tiene el sentido actual de déspota, sino que indicaba a quién ejercía el mando, sin tener derecho. Los tiranos favorecieron el desarrollo económico e industrial y mejoraron la situación del pueblo, pero luego trataron de perpetuarse con sus hijos, fundando verdaderas dinastías.» (Astolfi $1953,108)$

En estas descripciones hay cuatro elementos que denotan tensión: el detenimiento en la emergencia de un sujeto político novedoso y popular («marineros, empleados», etc.), la aparición de personalidades escaladoras, la concentración del poder sin legitimidad y, por último, el carácter incierto y experimental de la situación. La enseñanza de la Historia antigua no se pierde, muy por el contrario, constituye un campo propicio para inducir a una reflexión sobre las condiciones políticas del presente.

No podemos terminar esta exposición sin dar lugar al manual que durante esta época redacta José Luis Romero, el medievalista que introdujo en Argentina la historia social y el pensamiento de la escuela de los Annales casi al mismo tiempo en que se estaba produciendo (Waiman 2015).

Como Palacio en su momento, Romero identificó en las aulas secundarias un canal magnífico para hacer circular ideas sobre la sociedad y sobre el presente. Publicado en 1952, el manual de Romero constituye una propuesta de avanzada para la época, tanto en su presentación gráfica, como en la integración de las fuentes y las ideas didácticas. Aquí Pisístrato aparece como la peor solución 
a un cambio histórico complejo e inevitable 7 . Lo más medular del libro de Romero, sin embargo, es que a través de sus páginas ofrece a los jóvenes lectores de clase media un programa de acción alternativo que acepta el cambio social y limita el poder de las aristocracias terratenientes ${ }^{8}$.

A lo largo del periodo peronista, en síntesis, el tratamiento de la Historia clásica como campo de exploración de ideas y proyectos de acción no ha menguado; por el contrario, se advierte fortalecido por el flujo de posturas diversas. Al igual que en el resto de las etapas examinadas, lo que otorga sentido a la enseñanza de esta parcela son los conceptos de herencia y progreso. Ante todo, estos contenidos se enseñan en las aulas porque se quiere asentar la idea de la sociedad argentina como parte activa de un mundo civilizado, por un lado; y la hipótesis central que estas tierras todavía prometen algo, por el otro. Si de esa orilla del Atlántico ya no hay utopía, por lo menos hay movilidad social.

\section{Conclusiones}

Como apuntan todas las contribuciones que forman parte de este dossier, las sociedades contemporáneas han fraguado los canales más diversos para movilizar valores cívicos que tienen como centro y referencia a la Antigüedad grecorromana. A partir del siglo xIX - y en el caso argentino, desde fines de aquel siglo - la escuela ha constituido uno de los dispositivos con mayor capacidad para proponer este modelo a un público amplio y convertirlo en campo de discusión. La escuela ha contribuido y mucho en la instalación de esa relación especular que es la tradición, en la cual la sociedad contemporánea se mira en su modelo y su modelo aparece como aquello que se quiere ver.

En el caso argentino en particular, esta combinación de herencia y progreso movilizada por la escuela ha resultado tan eficaz, que sirvió también para desdeñar toda creación diferente de Atenas, todo lazo ajeno a Roma, en fin, toda aquella producción social que no encuentre lugar en la tradición europea. Como reacción a este desdén, en los últimos años — como ya hemos visto- se ha buscado desactivar la idea de una herencia europea: la Argentina es hija de sí misma o comparte su destino con los países víctimas de la conquista. A la versión esquemática de la Argentina europea, la escuela opone para consumo de las nuevas generaciones una visión revisionista y simplificatoria del pasado común.

\footnotetext{
7 «Pese a la prudencia de sus disposiciones y al equilibrio social que prometían las leyes de Solón, su obra tuvo la virtud de no dejar satisfechas a ninguna de las partes (...). Los eupátridas procuraron recuperar sus perdidas ventajas y los colonos, en cambio, se mostraron desilusionados porque esperaban que les fueran entregadas tierras para trabajar... Entretanto, los más pobres de todos, los que formaban parte de la clase de los tetes y se ocupaban de los diferentes oficios, consideraban que nada habían ganado y se mostraban inquietos e insatisfechos. La ocasión parecía favorable para que las clases más humildes se sublevaran nuevamente, y esa ocasión fue aprovechada por Pisístrato, un eupátrida que aspiraba al poder, y se presentó como el jefe de las clases desheredadas. Con su apoyo se apoderó del poder (...) e instauró una tiranía, es decir, un régimen ilegal que
}

concentraba en sus manos todo el poder sin que tuviera que dar cuentas a nadie» (Romero 1952, 119).

${ }^{8}$ Este es uno de los modos: «Pero esas conquistas [de Dracón] no podían satisfacer a las clases oprimidas. A medida (...) que pasaba el tiempo, se desarrollaban más y más la vida industrial y comercial, y la clase media adquiría cada vez más importancia. En consecuencia, cada vez se mostraba más insatisfecha con el poder omnímodo que poseía la aristocracia noble terrateniente y aspiraba a apoderarse del poder político o al menos participar en él de alguna manera. (...). La clase media podía contar con el apoyo de la clase más humilde, y con ella su fuerza se acrecentaba y ponía en serio peligro al régimen aristocrático, en cuyo beneficio estaban hechas las leyes vigentes» (Romero 1952, 116). 
Ninguna reforma educativa ha osado sin embargo revisar la idea de progreso. Esquema insostenible en la Argentina, irreal, completamente reaccionario: la escuela propone un pasado retrógrado para confrontarlo a un presente tecnologizado y de libertades virtuales conquistadas. La escuela insiste con lo que sin duda es una sustancialización del presente, y acaso sea uno de los pocos dispositivos en Argentina que se aferra a la idea de un progreso superador. Si dejáramos caer definitivamente esta idea, el aula podría resultar un espacio de intercambio más interesante.

\section{BibLIOGRAFÍA}

Artieda, T., 2009, «Escenas de lectura en los textos peronistas (1946-1955)», en: R. Spregelburd, M. C. Linares (eds.), La lectura de los manuales escolares. Textos e imágenes, Luján: UNLU-UNN, 159-178.

Astolfi, J., 1953, Sintesis de Historia Antigua, Buenos Aires: Kapelusz.

Astolfi, J., A. Pasquet \& C. De Repetto, 1949, Europa civilizada. Conocimientos básicos. Serie para Gto. Grado, Buenos Aires: Kapelusz.

Berard, E., 1995, «Faut-il contextualiser les manuels?», en: J. Pecheur, G. Vigner (eds.), Méthodes et méthodologies. Le Français dans le monde, Paris: Edicef, 21-24.

Censo Provincial de Matricula Educativa 2017, Febrero 2018, Resultados definitivos, Buenos Aires: Ministerio de Economía, Subsecretaría de Política y Coordinación Económica, Dirección de Estadística.

Corbiere, E., 1990, Mamá me mima, Evita me ama. La educación argentina en la encrucijada, Buenos Aires: Sudamericana.

Diseño curricular para la Educación Secundaria, 1er. Año (7mo. Escuela Secundaria Básica), 2006, Buenos Aires: Dirección General de Cultura y Educación, Gobierno de la Provincia de Buenos Aires, 75-77.

Dussel, I., 1997, Curriculum, Humanismo y Democracia en la Enseñanza Media (1863-1920), Buenos Aires: Flacso-CBC-UBA.

Finocchio, S., 2009, «El estudio histórico de la cultura escolar», Memoria Académica, La Plata: FaHCE Universidad Nacional de La Plata (recuperado de: http://www.memoria.fahce.unlp.edu.ar/programas/ pp.6646/pp.6646.pdf).

Gutiérrez, L., \& L. A. Romero, 1995, Sectores populares. Cultura y politica. Buenos Aires en la entreguerra, Buenos Aires: Sudamericana.

Halperín Donghi, T., 2003, La Argentina y la tormenta del mundo. Ideas e ideología entre 1930 y 1945, Buenos Aires: Siglo XXI.

Linares, M. C., 2009, «Los libros de lectura en Argentina: sus características a lo largo de los siglos», en: R. Spregelburd, M. C. Linares, La lectura de los manuales escolares. Textos e imágenes, Luján: UNLUUNN, 47-58.

MarTínez, J., 1922, Historia de la civilización, Buenos Aires: Librería de Ángel García [2.a edición].

Nieburg, F., 1988, Los intelectuales y la invención del peronismo. Estudios de antropología social y cultural, Buenos Aires: Alianza.

Palacio, E., 1939, Historia de Roma, Buenos Aires: Albatros.

PasQuale, R., 2009, «De espejos y eclipses. Cultura nacional y cultura extranjera en los manuales de francés contextualizados» en: R. Spregelburd, M. C. Linares, La lectura de los manuales escolares. Textos e imágenes, Luján: UNLU-UNN, 71-80.

Pearson, I., 1938, Historia de Oriente, Grecia y Roma para Primer año de colegios nacionales, Buenos Aires: Manuel Tato ed.

Pisano, N., 1953, Historia Antigua y Medieval para Enseñanza media, Buenos Aires: Editorial Estrada.

Rock, D., S. Mageedeutsch, M. Rapalo, R. Dolkart, D. Lvolich, L. Senkman \& P. Lewis, 2001, La derecha argentina. Nacionalistas, neoliberales y clericales, Barcelona-Bogotá-Buenos Aires: Javier Vergara.

Romero, J. L., 1952, Historia de la Antigüedad y Edad Media para la enseñanza de escuela media, Buenos Aires: Editorial Estrada. 
Somoza Rodríguez, M., 2006, Educación y politica en Argentina (1946-1955), Buenos Aires: Miño y Dávila-UNED.

Somoza Rodríguez, M., 1997, "Una mirada vigilante. Educación del ciudadano y hegemonía en Argentina (1946-1955)», en: H. Cucuzza, Estudios de Historia de la Educación durante el primer peronismo (1946-1955), Buenos Aires: Los libros del Riel.

Trevisán, H., \& J. Sinland, 1925, Manual de historia de la civilización, Buenos Aires: Librería de Ángel Santos [3. a edición].

Waiman, D., 2015, «Producción de manuales para la enseñanza media en José Luis Romero: su idea de historia total», VIII Jornadas Nacionales y I Congreso Internacional sobre la Formación del Profesorado (http:// docplayer.es/15285807-Produccion-de-manuales-para-la-ensenanza-media-en-jose-luis-romero-su-ideade-historia-total-1.html 